\title{
Testing the Level of Knowledge of Physical Fitness among the Employees of Hashemite University
}

\author{
Mahmoud AL-Haliq, ${ }^{1, *}$ Esam Abu-Shihab ${ }^{2}$, Manal Al-Kloub ${ }^{3}$, Ibrahim Harafsheh ${ }^{1}$ \\ ${ }^{1}$ College of Physical Education and Sport Sciences, The Hashemite University, Jordan \\ ${ }^{2}$ Department of Physical Education, The Mutah University, Jordan \\ ${ }^{3}$ Department of Maternal Child and Family Health, The Hashemite University, Jordan
}

Received December 13, 2020; Revised January 14, 2021; Accepted February 18, 2021

\section{Cite This Paper in the following Citation Styles}

(a): [1] Mahmoud AL-Haliq, Esam Abu-Shihab, Manal Al-Kloub, Ibrahim Harafsheh, "Testing the Level of Knowledge of Physical Fitness among the Employees of Hashemite University," International Journal of Human Movement and Sports Sciences, Vol. 9, No. 1, pp. 156 - 162, 2021. DOI: 10.13189/saj.2021.090122.

(b): Mahmoud AL-Haliq, Esam Abu-Shihab, Manal Al-Kloub, Ibrahim Harafsheh (2021). Testing the Level of Knowledge of Physical Fitness among the Employees of Hashemite University. International Journal of Human Movement and Sports Sciences, 9(1), 156 - 162. DOI: 10.13189/saj.2021.090122.

Copyright $\bigcirc 2021$ by authors, all rights reserved. Authors agree that this article remains permanently open access under the terms of the Creative Commons Attribution License 4.0 International License

\begin{abstract}
Physical fitness is one of the most important indicators of adults' health and low mortality. The mastery of cognitive physical fitness and the methods of its application may help in improving performance. The need to engage this concept in sporting activities for both genders becomes vital for the value and benefits that reap through it. This study aimed at identifying the cognitive level test of physical fitness for female employees of the Hashemite University. Using a descriptive design, 135 female employees were surveyed by a questionnaire which consisted of (39) items testing the cognitive level of the university's faculty and staff. Data were analyzed using SPSS version 21 (SPSS, Inc., Chicago, IL, USA). Arithmetic means and standard deviations were also applied to measure the cognitive level in physical fitness. Three-way ANOVA was used to analyze the effect of the independent variables (scientific qualification, experience, job title) on the knowledge outcome of female employees. The results revealed that there was no statistically significant effect of the independent variables on the cognitive results of female employees, because their true significance levels were $(0.324,0.76,0.379)$ respectively. Hence, all of them were greater than the real significance level $(\alpha \leq 0.05)$, which indicates a lack of significant differences in these variables. Accordingly, the researchers recommend establishing special ladies' facilities to increase sport activities, and conducting more special courses to develop the elements of fitness, including wider segment of female employees.
\end{abstract}

Keywords Knowledge, Physical Fitness, The Hashemite University

\section{Introduction}

Rapid and comprehensive change has become a feature of the contemporary civilization, in which, a driving force in its movement and dynamism at the same time is among these features. A man hardly adapts himself to one of the discoveries of science until he finds himself facing a cultural shock that needs another adaptation [1].

Because of this development, physical knowledge has become a bright and rich cultural and sophisticated face, that the contemporary man who is in dire need for health, fitness, and physical culture worthy of being familiar with [2]. It is also considered an engine and influencing the natural growth process of the human being and it is directly affecting the increase of productive capacities [3].

In the recent decades, the development of the concept of fitness and the need to engage in sporting activities for both genders and ages, necessitate its value and the benefits it reaps [3]. The cognitive outcome is one of the most important aspects of the mathematical field. The greater the mastery of this cognitive outcome and the methods of its application, the greater the ability to improve performance [4].

Physical activity is required to stay alive, including 
physical fitness, which is one of the significant indicators of adult health and low mortality [5-6-7]. According to (Granacher, U. et al, 2011 \& Antonio, G.et al, 2018), the combined exercises for balance and strength in the lower extremities of the body improve normal walking speed performance after 8 weeks in middle-aged workers. Higher levels of upper and lower body muscle strength are associated with the lower risk of death in the adult population, regardless of age and period of follow-up [8-9].

A research conducted to study the associations between measures of cardiorespiratory fitness (CRF) and cardiovascular interaction with stressors in adults revealed that, individuals with higher levels of cardiorespiratory fitness (CRF) rated lower values of a heart rate reaction as a physiological measure of acute stress [10]. After 24-week resistance training on cognitive performance in sedentary older adults, it was found that a significant improvement in maximum strength on short- and long-term memory and attention have occurred. [11].

\section{Problem Statement}

In late decades, there has been a great development in the concept of sports and the need to perform it for both genders, owing to its numerous benefits to health, nevertheless, the scientific and knowledge revolution in the field of health. Technological developments have led to the lack of movement and laziness in practicing physical activity, which in turn led to the spread of many diseases of the time. Despite the advanced sports facilities at the campus, the researchers have noticed that the female employees of the university have less drive and desire for practicing sports activities compared to their numbers and the facilities availability. Notwithstanding, the continuous encouragement from the university administration, the presence of the faculty of physical education and sports sciences on the university campus. From this standpoint, the problem of this study appeared in an attempt to identify the reasons for the lack of momentum in practicing sports activities by measuring the knowledge outcome of a sample of female employees at the university.

\section{Literature Review}

The study of (Obeidat \& Alzebat, 2014) aimed at identifying the cognitive level test in physical fitness for employees of Irbid University. A questionnaire was designed and distributed to the study sample which consisted of (103) participants. The sample was chosen randomly from the study population. The results showed that, an average level of physical fitness among the employees of Irbid University occurred, and the existence of statistically significant differences at the level of significance $(0.05 \leq a)$ on the variable (academic qualification) in the favor of the category (Bachelor). Also, there were no statistically significant differences at the significance level $(0.05 \leq \mathrm{a})$ on the level of physical fitness according to other personality variables (number of years of experience, job title) [3].

Both (Baker \& Ahmed, 2020) studied the knowledge outcome in the field of physical fitness among students of the college of sport-sciences at the University of Mu'tah, using the descriptive method for a study sample consisting of (189) of both genders randomly selected. The results of the study revealed that there were no differences between both sexes. But there were statistically significant differences for both the academic year and grade variables. It recommended that the physical fitness course shall be given the sufficient importance by the college administration, and fitness courses are to be a prerequisite and compulsory for all practical subjects [12].

The study of (Al-Sharif, 2019) identified the differences in the degree to which trainers working in fitness centers possess cognitive competence of health-related fitness in Jeddah, according to the variables (academic qualification, number of years of experience). The researcher used the descriptive method, and the cognitive test as a study tool. However, the size of the sample was (142) trainers randomly selected. The results presented that coaches have a cognitive competence above the middle in the field of sports training, in the field of physical fitness tests and in the field of nutrition. Plus, coaches have weak cognitive competence in the field of training physiology [13].

(Katharina, et al., 2019) studied the effect of cardiovascular and motor fitness on cognitive performance in subjects interested to prevention and early detection of Alzheimer's disease (AD). The test was applied to a sample of (338) participants. Their ages ranged between 50-85 years old. Participants were grouped into three groups (no cognitive impairment (NCI), mild cognitive impairment of the amnestic type (MCIa), and mild AD (mAD) through neuropsychological evaluation and third-party history, which is clinical, laboratory, or imaging investigations. Subjective memory impairment (SMI) and cognitive syncope (Cognitive blackouts) were recorded. Cardiorespiratory fitness (CRF) was assessed by a two-minute step test and motor fitness (MF) by a pregnancy test Chair for 30 seconds. Those suffering from low (Cardiorespiratory fitness CRF) and MF (motor fitness) performed poor in different cognitive domains, and had a higher score in cases of cognitive loss of consciousness, often SMI. The study concluded that decreased CRF and MF they are associated with impaired cognition [14].

The study of (Ho T-W et al., 2020) aimed at finding out the level of self-awareness among Taiwanese adults in physical fitness and exercise prescription. Collecting demographical data, anonymous cross-sectional survey was performed using research electronic data capture. The tests were; physical fitness cognitive investigation and 
exercise prescription, the physical fitness cognitive test and exercise prescription, and the physical examination prompt fitness assessment. The questionnaire was answered by 200 respondents. The results showed a severe absence of awareness of health-related fitness, exercise prescription, and exercise progress planning. 98\% of people do not know the latest recommended guidelines for physical activity, although most agree that fitness and exercise are good for health [15].

(Olaf Prieske et al., 2019) conducted a study that aimed at examining physical fitness and psychological cognitive functioning associated to youth and middle-aged workers in light of physical and mental work activities. The sample consisted of (73 men and 75 women). They were grouped into groups that involved mental (MD) or physical (PD) at work. Workers in MD showed better measures of fitness (balance, extensor muscle endurance of the trunk), performance perception, and lower levels of perceived stress compared with workers in PD [16].

\section{Research questions}

What is the cognitive level of physical fitness among female employees of the Hashemite University?

Does the knowledge level differ in the physical fitness of the Hashemite University employees?

Research Objectives: The study aimed at identifying the cognitive level test in physical fitness among female employees of the Hashemite University.

\section{Limitations of the Research}

- The human field: The Hashemite University.

- The temporal domain: 6/8/2020 - 1/9/2020.

- Spatial domain: The research sample is limited to female employees at the Hashemite University.

\section{Research Methodology and Procedures}

The used method: due to its suitability for the nature of this research, descriptive comprehensive survey approach was used.

Research population: The study population consists of 450 employees of the Hashemite University.

Research sample: The original research sample consisted of (130) female employees of the Hashemite University, chosen randomly from the research population. Table (1) shows the distribution of the sample members according to personal variables:
Table 1. Distribution of the sample members according to personal variables

\begin{tabular}{|c|c|c|c|}
\hline Variables & Category & Repetition & percentage \\
\hline \multirow{5}{*}{ Qualification } & $\begin{array}{c}\text { Secondary then } \\
\text { less }\end{array}$ & 8 & 6.1 \\
\hline & diploma & 33 & 25.3 \\
\hline & Bachelor & 36 & 27.6 \\
\hline & Postgraduate & 53 & 40.7 \\
\hline & Total & 130 & 100.0 \\
\hline \multirow{4}{*}{$\begin{array}{c}\text { Years of } \\
\text { Experience }\end{array}$} & 5 years or less & 24 & 18.4 \\
\hline & $6-10$ years & 45 & 34.6 \\
\hline & $\begin{array}{c}10 \text { years and } \\
\text { older }\end{array}$ & 61 & 46.9 \\
\hline & Total & 130 & 100.0 \\
\hline \multirow{3}{*}{ Job title } & Administrative & 78 & 60.0 \\
\hline & $\begin{array}{c}\text { education } \\
\text { institution }\end{array}$ & 52 & 40.0 \\
\hline & Total & 130 & 100.0 \\
\hline
\end{tabular}

The validity of the research evidence: The court questionnaire was used by the study of (Farhat, 2001) as it was appropriate to the nature of the Jordanian environment [4].

Stability of the research tool: Using the method of testing and re-testing, the consistency of performing the test was found on an exploratory sample consisting of (30) female employees from the Hashemite University, and was re-applied to the same sample after an interval of two weeks. (Pearson Correlation) and (Cronbach Alpha) measurements were used and showed a high and acceptable values for the purposes of the study.

Research implementation procedures: In order to achieve the objectives of the research, the following procedures and steps were followed:

- A questionnaire which is commensurate with the characteristics and environment of the Jordanian society and the research the nature [3].

- The research population was determined, and then a representative sample of the research community was chosen randomly.

- For the purposes of data collection, the research tool was distributed to the sample members.

- The statistical analysis using SPSS version 22 of the social sciences package was used to analyse the data collected from the questionnaires, along with the following:

- Arithmetic mean and standard deviation.

- 3-Way ANOVA.

- Cronbach's alpha: is coefficient of internal consistency. It is usually used as an estimate of the reliability of a researcher's test for a sample of study.

- Frequencies and percentages were extracted. 


\section{Research variables:}

First: the independent variables

Academic qualification: consisted of 4 categories (secondary or less, diploma, bachelors, and postgraduate).

- The number of years of experience: divided into 3 categories (5 years or less, 10 years, 10 years and more).

Job title: consisted of 2 categories (administrative and education institution).

\section{Second: the dependent variable:}

The knowledge level in physical fitness of the Hashemite University employees.

\section{Presentation and Discussion of Results}

\section{First: Results related to answering the first question:}

The first question: What is the knowledge level in physical fitness of the Hashemite University employees?

To answer this question, arithmetic averages and standard deviations were calculated for the cognitive level items in physical fitness of the Hashemite University employees. Table (2) explains:

Table 2. Arithmetic means and standard deviations to measure the cognitive level in physical fitness of the Hashemite University employees

\begin{tabular}{|c|c|c|c|c|c|}
\hline $\mathbf{N}$ & Paragraph & $\mathbf{M}$ & SD & $\begin{array}{l}\text { lowest } \\
\text { value }\end{array}$ & $\begin{array}{c}\text { highest } \\
\text { value }\end{array}$ \\
\hline 1 & Physical fitness means the competence of an individual in meeting the demands of life & 3.97 & .956 & 1 & 5 \\
\hline 2 & Fitness aims at developing the elements of physical fitness & 4.17 & .706 & 2 & 5 \\
\hline 3 & Physical fitness is the ability to perform the chores of daily life without getting tired & 4.13 & .893 & 1 & 5 \\
\hline 4 & Physical fitness is keeping the body healthy and free from diseases & 4.32 & .661 & 2 & 5 \\
\hline 5 & $\begin{array}{c}\text { Physical fitness increases a person's ability to perform wide range of movements in all } \\
\text { joints }\end{array}$ & 4.32 & .705 & 2 & 5 \\
\hline 6 & Fitness increases muscle strength & 4.28 & .800 & 1 & 5 \\
\hline 7 & Physical fitness strengthens neuromuscular compatibility & 4.27 & .814 & 1 & 5 \\
\hline 8 & Physical fitness works on coordination in motor performance & 4.39 & .731 & 1 & 5 \\
\hline 9 & Fitness helps improving performance of the heart muscle & 4.32 & .809 & 1 & 5 \\
\hline 10 & Physical fitness increases the number of heartbeats & 3.48 & 1.259 & 1 & 5 \\
\hline 11 & Physical fitness increases blood pressure & 3.85 & 1.096 & 1 & 5 \\
\hline 12 & The environment affects fitness & 4.23 & .742 & 2 & 5 \\
\hline 13 & Warming up is necessary before sporting activity & 4.24 & .870 & 1 & 5 \\
\hline 14 & Fitness builds strength and endurance & 3.25 & 1.387 & 1 & 5 \\
\hline 15 & Physical fitness means being overloaded & 3.52 & 1.228 & 1 & 5 \\
\hline 16 & The body takes a long time to gain fitness & 3.93 & 1.036 & 1 & 5 \\
\hline 17 & A person's physique develops with a drive to develop this fitness & 3.89 & 1.150 & 1 & 5 \\
\hline 18 & Cultural and health awareness of the role of fitness are conditions to physical fitness & 3.82 & 1.126 & 1 & 5 \\
\hline 19 & Physical diversity helps the body grow faster & 3.98 & .952 & 1 & 5 \\
\hline 20 & $\begin{array}{l}\text { Physical fitness exercises help to strengthen the physical and vital aspects to create the } \\
\text { motor characteristics essential for great achievement }\end{array}$ & 4.25 & .798 & 1 & 5 \\
\hline 21 & Fun and interesting exercises help my persistence in performing fitness exercises & 4.15 & .960 & 1 & 5 \\
\hline 22 & A trainer helps in cognitive development about the importance of fitness & 4.07 & 1.065 & 1 & 5 \\
\hline 23 & $\begin{array}{c}\text { Technical talents and physical abilities help in developing my knowledge and in } \\
\text { increasing my self-confident }\end{array}$ & 3.92 & 1.039 & 1 & 5 \\
\hline 24 & Facilitate awareness and knowledge develops my abilities when practicing fitness & 3.75 & 1.195 & 1 & 5 \\
\hline 25 & $\begin{array}{l}\begin{array}{l}\text { Sport-culture is a driver for the growth of an individual's natural process; mental and } \\
\text { emotional }\end{array} \\
\end{array}$ & 3.90 & 1.033 & 1 & 5 \\
\hline 26 & Sport-culture is a spiritual and material value that helps individual developing it better & 3.85 & 1.138 & 1 & 5 \\
\hline 27 & Fitness strength factors are essential for good looks and skill performance & 3.99 & .952 & 1 & 5 \\
\hline 28 & $\begin{array}{l}\text { Muscular endurance helps athlete to perform movement and overcome fatigue for a long } \\
\text { period of time }\end{array}$ & 3.85 & 1.028 & 1 & 5 \\
\hline
\end{tabular}


Table 2 continued

\begin{tabular}{|c|c|c|c|c|c|}
\hline $\mathbf{2 9}$ & $\begin{array}{c}\text { Sport-culture helps individual's ability to rapidly react between the emergence of a } \\
\text { specific stimulus and the initiation of a motor response }\end{array}$ & 4.17 & .799 & 1 & 5 \\
\hline $\mathbf{3 0}$ & Fitness exercises increase the strength and activity of the heart muscle & 3.36 & 1.318 & 1 & 5 \\
\hline $\mathbf{3 1}$ & Fitness may build wrong and unhealthy habits & 3.85 & 1.178 & 1 & 5 \\
\hline $\mathbf{3 2}$ & It takes a while for a physique to have an effect on the body & 4.13 & .927 & 1 & 5 \\
\hline $\mathbf{3 3}$ & Fitness corrects the wrong postures and gives the individual a healthy appearance & 3.92 & 1.104 & 1 & 5 \\
\hline $\mathbf{3 4}$ & Physical fitness develops leadership qualities & 4.09 & .960 & 1 & 5 \\
\hline $\mathbf{3 5}$ & Fitness increases the individual's productive efficiency, that affects the submitted \\
physical and mental work effort & 4.18 & .830 & 2 & 5 \\
\hline $\mathbf{3 6}$ & Fitness improves the individual's ability to relax, judge and reduce muscle tension & 4.02 & 1.007 & 1 & 5 \\
\hline $\mathbf{3 7}$ & Fitness increases the individual's ability to resist diseases, whether infectious or chronic & 4.18 & .840 & 2 & 5 \\
\hline $\mathbf{3 8}$ & Physical fitness enables the ability to perform movements of a large range without \\
tearing ligaments and muscles & 4.24 & .766 & 2 & 5 \\
\hline $\mathbf{3 9}$ & Physical fitness maintains the shape and stability of the body without negative effects & 4.28 & .747 & 2 & 5 \\
\hline & Domain as a whole & 4.0128 & .38187 & 3.05 & 4.72 \\
\hline
\end{tabular}

Table 3. Arithmetic means and standard deviations of the tool as a whole according to the independent variables (academic qualification, number of years of experience, job title).

\begin{tabular}{|c|c|c|c|c|c|c|}
\hline Variables & Level & number & lowest value & highest value & M & SD \\
\hline \multirow{4}{*}{ Qualification } & Secondary then less & 8 & 3.05 & 4.59 & 3.7404 & .48562 \\
\cline { 2 - 7 } & diploma & 33 & 3.08 & 4.72 & 3.9643 & .43106 \\
\cline { 2 - 7 } & Bachelor & 36 & 3.10 & 4.62 & 4.0192 & .39273 \\
\cline { 2 - 7 } & Postgraduate & 53 & 3.36 & 4.56 & 4.0798 & .30714 \\
\hline \multirow{4}{*}{ Years of Experience } & 5 years or less & 24 & 3.05 & 4.72 & 4.0373 & .44141 \\
\cline { 2 - 7 } & 6-10 years & 45 & 3.08 & 4.59 & 3.9020 & .39520 \\
\cline { 2 - 7 } & 10 years and older & 61 & 3.10 & 4.62 & 4.0803 & .34028 \\
\hline \multirow{2}{*}{ Job title } & Administrative & 78 & 3.05 & 4.72 & 3.9609 & .42223 \\
\cline { 2 - 7 } & education institution & 52 & 3.36 & 4.56 & 4.0907 & .29896 \\
\hline
\end{tabular}

Table 4. Results of triple covariance analysis of the effect of independent variables on the questionnaire as a whole

\begin{tabular}{|c|c|c|c|c|c|c|}
\hline Source & Sum of squares & $\begin{array}{c}\text { Degree of } \\
\text { freedom }\end{array}$ & $\begin{array}{c}\text { Average of } \\
\text { squares }\end{array}$ & Value (F) & $\begin{array}{c}\text { SIG } \\
\text { level }\end{array}$ & SIG \\
\hline Qualification & .484 & 3 & .161 & 1.171 & .324 & NO \\
\hline Experience & .968 & 3 & .323 & 2.344 & .076 & NO \\
\hline Job title & .107 & 1 & .107 & .781 & .379 & NO \\
\hline error & 16.797 & 122 & .138 & & & \\
\hline Total & 2112.166 & 130 & & & & \\
\hline
\end{tabular}

Table (2) shows that the arithmetic averages ranged between (4.39-3.25), the highest paragraph (8), which states, "Physical fitness works on coordination in motor performance," and in the last place is paragraph (14) which states, "Fitness builds strength and endurance". Where, the arithmetic average for the field as a whole is (4.0128), which indicates that the level of knowledge outcome among the employees of the Hashemite University came to a high level.

Results related to the answer to the second question: Does the cognitive level of physical fitness among female employees of the Hashemite University differ according to the independent variables (academic qualification, experience, administrative title)?

To answer this question, the arithmetic averages and standard deviations of the tool as a whole were calculated in light of the independent variables (academic qualification, number of years of experience, job title), and then the triple variance analysis (3-Way ANOVA) was applied to measure the effect of the independent variables on the questionnaire as a whole. tables $(3,4)$ illustrate.

From the above table 3 , it is clear that there was a strong variation in the arithmetic means of the levels of 
the independent variables, which indicates the existence of differences between these levels of the tool as a whole. To reveal whether these differences are statistically significant, triple analysis of variance was used. Table (4) illustrates that.

The table 4 shows that there were no statistically significant in the effect of the independent variables (scientific qualification, experience, job title) on the knowledge outcome of female employees, as their significance levels are $(0.324,0.76,0.379)$ respectively, and all of them are greater than the significance level $(\alpha \leq 0.05)$. This indicates that there were no significant differences among these variables.

Discussing the first question: What is the cognitive level of physical fitness among the female employees of the Hashemite University?

The results of the first question showed that the paragraph that states, "Physical fitness works on coordination in motor performance" has gained the highest arithmetic averages, while the paragraph that states " Fitness builds strength and endurance" has occupied the last rank. The researcher attributes this result to the fact that most people have a great belief that the exercise of sports has a great impact on the human body and motor performance, which avoids the occurrence of deformities in general. Where both (Zeyad, 2017), (Zeyad, 2014) study [17-18], (Leonard, 2010), (Hazzaa, 2000) [19-20], indicate that physical fitness is one of the basic components of an individual's health, as it enables individual to perform the daily life activities and functions to the max, owing to its direct consequence on health, personality and body. The study of (Al- Jafar, 2015), (Zeyad, 2014), (Murray et al., 2014), (Bret, et.2014) [21, $18,22,23]$, confirmed that improving physical fitness has a positive effect on maintaining a healthy human body free from disease and posture deformities, correcting part of wrong physical and movement behavioral habits, giving the individual a healthy and consistent figure, increasing the effectiveness of the immune system to resist diseases. These results contrast with the study of (Te-Wei Ho et al., 2020) [15], which revealed that there is a lack of awareness of health-related fitness, exercise prescription, and exercise planning progress, although most agree that physical, fitness and exercise are good for health.

Discussion of the second question: Does the customary level of physical fitness among the Hashemite University employees differ according to the independent variables (academic qualification, experience, administrative title)?

The results showed that the variables of the study (academic qualification, experience, administrative title) had no effect on the knowledge level of the Hashemite University employees. The reason for this finding is due to the presence of the faculty of physical education and sports sciences on the campus of the Hashemite University, which holds free courses for male and female employees. Which in turn was the reason for the high level of knowledge of the study sample. This study is in agreement with the study by (Ameera, 2017) [24], which indicates a high level of motivation to exercise physical fitness among women in fitness centers in the governorates of the northern West Bank. While both the study of (Lobne 2009), (Saa‘a and Diabat, 2014) [3, 26], indicate that there was no statistical significance in the variables (number of years of experience, job title), with an average level of knowledge achievement among the employees of Irbid National University. In contrast to the study of (Laet, 2014) [25], which revealed a weakness of cognitive competence in sporting modernity among the employees (teachers) of sports education in the city of Mosul.

\section{Conclusions}

1. The level of the knowledge outcome of the physical fitness among the female employees of the Hashemite University was significantly high.

2. The independent variables (academic qualification, experience, scientific qualification) did not show any effect on the level of knowledge outcome of the Hashemite University employees.

\section{Recommendations}

1. Conducting more special courses to develop physical fitness components to include the largest number of female employees.

2. Holding sports competitions between female employees to increase enthusiasm.

3. Establishing special facilities for women to increase the number of sports activity practices.

\section{REFERENCES}

[1] Dulaimi, Naheda Abdel Zaid. Abboud, Haidar Mahmoud, Ali, Agda Abbas Mohammed, "The level of positive thinking and its relation to the knowledge of volleyball," Journal of Human Sciences, Vol. 1, No 8. pp. 231-244, 2013.

[2] Walead, Al- Rahahleh, "Physical Fitness Cognitive Domain for the Students at Faculty of Physical Education at University of Jordan," Dirasat: Educational Sciences, Vol.34, pp. 635-644. 2007.

[3] Saa' a Obeidat, Najeh Diabat, "Testing the level of knowledge physical fitness among the employees of Irbid University Collage," The Scientific Journal of Physical and Mathematical Sciences and Techniques, Vol.11, pp. 67-95, 2014. 
[4] Farhat, Laila Al Sayed "Measurement and Testing in Physical Education, " Helwan University, Egypt, 2001

[5] Claude, Bouchard, Steven, N Blair, William L Haskell,” Physical activity and health, (2nd edition) ", Human Kinetics, Champaign, IL.2012

[6] Gisela, Sjøgaard, Jeanette, Reffstrup Christensen, Just, Bendix Justesen, Mike, Tina, Dalager, Gitte, Hansen Fredslund, Karen, Søgaard, "Exercise is more than medicine: the working age population's well-being and productivity "journal of Sport and Health Sci , Vol.5, No. 2, pp.159-165, 2016.

[7] Pieter, Coenen, Maaike A. Huysmans, Andreas Holtermann, Niklas Krause, Willem Van Mechelen, Leon M. Straker, Allard J, Van Der Beek, "Do highly physically active workers die early. A systematic review with meta-analysis of data from 193696 participants", British Journal of Sports Medicine Vol.52, No. 20, pp. 1320-1326, 2018.

[8] Granacher, U. Wick, C. Rueck, N. Esposito, C. Roth, R. Zahner, L. "Promoting balance and strength in the middle-aged workforce", Int J Sports Med, Vol. 32, No. 1, pp. 35-44, 2011b. DOI: 10.1055/s-0030-1267214.

[9] Antonio, García-Hermoso, Iván, Cavero-Redondo, Robinson, Ramírez-Vélez, Jonatan, R. Ruiz, Francisco, B. Ortega, Duck-Chul, Lee, Vicente, Martínez-Vizcaíno, "Muscular strength as a predictor of all-cause mortality in apparently healthy population: a systematic review and meta-analysis of data from approximately 2 million men and women", Archives of Physical Medicine and Rehabilitation, Vol.99, No.10, pp. 2100-2113,2018. DOI: 10.1016/j.apmr.2 018.01.008.

[10] Kathleen, Forcier, Laura, R. Stroud, George, D. Papandonatos, Brian, Hitsman, Meredith Reiches, Jenelle, Krishnamoorthy, Raymond, Niaura, "Links between physical fitness and cardiovascular reactivity and recovery to psychological stressors: a meta-analysis", Health Psychol Vol.25, No. 6, pp. 723-739, 2006. DOI: 10.1037/0278-613 3.25.6.723.

[11] Ricardo, C. Cassilhas, Valter, A. R. Viana, Viviane Grassmann, Ronaldo, T. Santos, Ruth, F. Santos, Sérgio Tufik, Marco, T. Mello, "the impact of resistance exercise on the cognitive function of the elderly", Med Sci Sports Exerc, Vol. 39, No.8, pp. 1401-1407, 2007. DOI: 10.1249/mss.0b013e318060111f.

[12] Baker, Althuneibat, Ahmed, Al-Thuneibat, "Identifying the cognitive outcome in physical fitness among students of the college of sports sciences at Mu'tah University", An-Najah University Journal of Human Sciences, Vol. 34, No.4, pp. 643-660, 2020.

[13] AL- Sharif, Muhammad, "the Efficiency Degree of Trainers' Knowledge in Health Related Physical Fitness at Health Club in Jeddah", Unpublished Master Thesis, Kingdom of Saudi Arabia, Department of Physical Education, University of Jeddah, 2019.

[14] Katharina, Gnosa, Agnies, Marczak, Jana, Binder, Georg, Adler, "Impact of Physical Fitness on Cognitive
Performance in Patients at a Memory Clinic", Dement Geriatr Cogn Disord Extra, Vol. 9, No. 1, pp. 129-135.2019. DOI: $10.1159 / 000496919$.

[15] Te-Wei, Ho, Hsing-Hua, Tsai, Jui-Fen, Lai, Sue-Min, Chu, Wan-Chung, Liao, Han-Mo, Chiu, " Physical fitness cognition, assessment, and promotion: A cross-sectional study in Taiwan, " PLoS ONE, Vol.15, No. 10, pp.1-18, 2020. https://doi.org/10.1371/journal.pone.0240137.

[16] Olaf, Prieske, Tina, Dalager, Vanessa, Looks, Kathleen, Golle, Urs Granacher, "Physical fitness and psycho-cognitive performance in the young and middle-aged workforce with primarily physical versus mental work demands, " Journal of Public Health: From Theory to Practice, 2019.https://doi.org/10.1007/s10389-019-01099-9.

[17] Zeyad, Zayed, " degree of knowledge efficiency of education teachers in health related fitness, "Journal of Sports Science and Physical Education, Vol. 1, No. 1, pp. 91-101, 2017.

[18] Zeyad, Zayed, "Exercise Physiology and Fitness. Scientific Publishing Center. King Abdul-Aziz University, Jeddah, 2014.

[19] Leonard, A. Kaminsky, "ACSM`s Health related physical fitness assessment manual $\left(3^{\text {rd }}\right.$. ed) " American college of sport Medicine, Lippincott Williams \& Wilkins, 2010.

[20] Hazzaa, Al-Hazzaa, "Physical Preparation," The Scientific Basis of Physical Activity Prescription for Health and Physical Fitness, Saudi Arabian Federation for Sports Medicine, Riyadh, 2000.

[21] Jafar, Al-Arjan, "the relationship of the predictive ability of health-related physical fitness and body fat percentage to the level of academic achievement among secondary school students in Jordan," Journal Manara, Vol. 21, No. 4/a, pp. 467-512, 2015.

[22] Murray, R. Barrick, Laura, Michael, K. Mount, "Self-monitoring as a Moderator of the Relationships between Personality Traits and Performance," Personnel Psychology, Vol. 58, No. 3, pp. 745-767, 2005. DOI: 10.1111/j.1744-6570.2005.00716.x.

[23] Bret, Alexander Beheim, Calvin, Thigpen, Richard McElreath, "Strategic social learning and the population dynamics of human behavior: the game of Go, " Evolution and Human Behavior, Vol.35, No. 5, pp. 351-357, 2014.

[24] Ameera, Shtawy, "Motivation for Physical Fitness Practice among the Women in Physical Fitness Center in the North of West North Bank Governorates," Unpublished Master Thesis, An-Najah University, Palestine, 2017.

[25] Laet, Shawkat, "the Degree of Possessing Cognitive Efficiency in Athletic Modernity by Physical Education in Mousil City /Iraq Teachers," Unpublished Master Thesis, Middle East University, 2014.

[26] Lobne, Abu Zhou, "the effect of sports practice on the degree of psychological compatibility of participants in fitness centers," Unpublished Master Thesis, Yarmouk University, 2009. 